\title{
PENINGKATAN PRODUKTIVITAS PETERNAK ITIK MELALUI PENERAPAN MESIN PENETAS TELUR
}

\section{IMPROVEMENT OF ITIC LIVESTOCK PRODUCTIVITY THROUGH THE APPLICATION OF EGG HATCHING MACHINES}

\author{
${ }^{1}$ Rany Puspita Dewi, ${ }^{2}$ Wandi Arnandi \\ ${ }^{\mathbf{1 , 2}}$ Program Studi Diploma III Teknik Mesin, Fakultas Teknik,Universitas Tidar \\ Jalan Kapten Suparman 39, Magelang 56116 \\ E-mail:ranypuspita@untidar.ac.id
}

\begin{abstract}
ABSTRAK
Sebagian warga masyarakat Desa Ngrajek, Kecamatan Mungkid, Kabupaten Magelang berprofesi sebagai peternak itik. Tujuan pelaksanaan kegiatan ini adalah untuk meningkatkan produktifitas peternak itik melalui penjualan anak itik, yang memiliki harga jual lebih tinggi melalui penerapan mesin penetas telur. Metode yang digunakan adalah difusi ipteks. Kegiatan ini dilaksanakan melalui dua tahap, yaitu : tahap pertama, observasi dengan melakukan metode pengumpulan data dokumentasi dan diskusi dengan tokoh masyarakat sebagai stakeholder. Hal ini bertujuan untuk memperoleh informasi kondisi real masyarakat peternak itik. Tahap kedua adalah tahap pengembangan solusi untuk menyelesaikan permasalahan yang dialami peternak itik melalui perancangan dan pembuatan mesin penetas telur serta mengadakan pelatihan pengoperasian mesin penetas telur. Hasil luaran utama yang dicapai dalam program ini adalah tersedianya mesin penetas telur. Hasil lain dari program ini adalah peningkatan wawasan dan pengetahuan tentang teknologi mesin penetas telur serta taraf hidup masyarakat Desa Ngrajek.
\end{abstract}

Kata kunci: Mesin Penetas Telur; Produktivitas; Peternak itik

\section{ABSTRACT}

Some residents of Ngrajek Village, Mungkid Subdistrict, Magelang Regency work as duck breeders. The purpose of this activity is to increase the productivity of duck breeders by selling ducklings, which have higher selling prices through the application of egg incubators. The method used is the diffusion of science and technology. This activity is carried out through two stages, namely: the first stage, the observation by conducting the method of collecting data documentation and discussion with community leaders as stakeholders. It aims to obtain information on the real condition of the duck farmer community. The second stage is the stage of developing solutions to solve the problems experienced by duck farmers through the design and manufacture of egg incubators and conduct training on the operation of egg incubators. The primary outcome achieved in this program is the availability of an egg incubator. Another result of this program is an increase in insight and knowledge about egg incubator technology and the living standards of the people of Ngrajek Village

Keywords: Egg Incubators; Productivity; Duck breeder

Submitted : 17 Mei 2019 Revision : 21 Juni 2019 Accepted : 20 Juli 2019

\section{PENDAHULUAN}

Desa Ngrajek terletak di Kecamatan Mungkid, Kabupaten Magelang yang berjaraksekitar $14 \mathrm{~km}$ dari pusat kota Magelang. Desa Ngrajek lebih dikenal dengan daerah penghasil ikan tawar dan wisata kuliner ikan tawar. Padahal sebagian masyarakat desa juga memiliki usaha peternakan itik. Selama ini 
pendapatan hanya berasal dari penjualan telur itik.

Peternak itik Desa Ngrajek rata-rata memiliki 30 ekor itik dengan dengan jumlah produksi telur sekitar 30 butir per hari. Pendapatan ini dapat ditingkatkan dengan menerapkan salah satu teknologi tepat guna yaitu mesin penetas telur. Melalui penerapan mesin penetas telur ini diharapkan dapat meningkatkan produksi itik yang pada akhirnya akan meningkatkan pendapatan peternak itik di Desa Ngrajek, karena satu buah anak itik memiliki harga jual sekitar 7000 per ekor. Harga jual ini lebih tinggi dibandingkan harga jual telur itik. Pendapatan peternak akan meningkat hampir $100 \%$ dengan perkiraan telur yang dapat ditetaskan sebesar $60 \%$ dari total telur yang dihasilkan.

Sandi (2015) menyatakan bahwa rendahnya jumlah produksi bibit itik dapat ditingkatkan dengan penerapan teknologi mesin tetas. Otomatisasi mesin tetas telur dapat meningkatkan daya tetas telur (Suyatno, 2005). Mesin tetas dengan menggunakan thermostat dapat menjaga kelembapan suhu di dalam dan penggunaan rak putar dapat memberikan kemudahan dalam proses penetasan telur (Ahaya, 2018).

Berdasarkan analisis situasi, terdapat permasalahan utama warga masyarakat Desa Ngrajek diantaranya yaitu: 1) Potensi ketersediaan telur itik yang belum dimanfaatkan secara optimal. Telur itik yang dihasilkan oleh sebagian warga masyarakat belum dimanfaatkan secara optimal. Hal ini dikarenakan telur itik yang dihasilkan masih dijual begitu saja. Padahal apabila dijual dalam bentuk anak itik dapat memiliki harga jual yang lebih tinggi dan dapat meningkatkan pendapatan warga masyarakat yang selain berprofesi sebagai petani juga berprofesi sebagai peternak. Rata-rata jumlah telur itik yang dihasilkan oleh warga masyarakat Desa Ngrajek adalah 30 butir telur per hari. 2) Minimnya pengetahuan dan wawasan masyarakat tentang mesin penetas telur.
Warga masyarakat Desa Ngrajek belum mengetahui teknologi tepat guna tentang mesin penetas telur. Pengetahuan mereka masih terbatas pada metode penetasan telur secara konvensional. Dimana pada metode ini induk itik akan mengerami telur itik dan tentu memerlukan waktu yang lebih lama. Melalui penerapan mesin penetas telur, peternak itik dapat menetaskan telur dalam jumlah yang banyak dan dalam waktu yang bersamaan. Mesin ini juga dapat digunakan secara terus menerus tanpa dipengaruhi oleh cuaca. Biaya pembuatan mesin ini juga relatif murah dengan cara pengoperasian yang mudah.

Target luaran dalam penerapan Program Kemitraan Masyarakat (PKM) bagi mitra yaitu berupa produk berupa mesin penetas telur dan peningkatan pemahaman dan keterampilan warga masyarakat Desa Ngrajek mengenai teknologi tepat guna melalui penerapan mesin penetas telur. Melalui penerapan mesin penetas telur, maka dapat meningkatkan kesejaheraan masyarakat karena adanya peningkatan produktifitas. Hal ini sesuai dengan enelitian yang dilakukan oleh (Rawung, 2018) yang menyatakan bahwa penggunaan mesin tetas dapat meningkatkan jumlah ayam kampung yang dipelihara oleh kelompok peternak dan meningkatkan penghasilan peternak dengan usaha menjual bibit ayam (DOC) kepeternak lain, dengan demikian dapat meningkatkan kesejahteraan kelompok peternak ayam.

\section{METODE}

Pelaksanaan kegiatan terbagi menjadi dua tahap. Tahap pertama yang dilakukan adalah observasi lokasi yang didukung metode pengumpulan data dokumentasi dan pendekatan dengan tokoh masyarakat sebagai stakeholder melalui diskusi bersama dengan warga masyarakat Desa Ngrajek, Kecamatan Mungkid, Kabupaten Magelang. Tahap ini dilakukan untuk mendapatkan informasi mengenai kondisi dan potensi yang bisa 
dikembangkan dari usaha peternakan itik.Mitrakegiatan Program Kemitraan Masyarakat adalah kelompok peternak itik yang berjumlah sekitar 5-10 orang. Mayoritas peternak itik masih mendapatkan penghasilan dari penjualan telur itik dan belum memilki pengetahuan yang cukup mengenai mesin penetas telur. Pengetahuan mereka masih terbatas pada penetasan secara konvensional.

Berdasarkan hasil observasi dan diskusi dengan warga masyarakat, telah ditemukan beberapa masalah, yaitu :

1) Potensi ketersediaan telur itik yang belum dimanfaatkan secara optimal.

2) Minimnya pengetahuan dan wawasan masyarakat tentang mesin penetas telur.

Tahap selanjutnya adalah identifikasi, analisis data observasi dan diskusi dari tahap pertama untuk pengembangan solusi. Pengembangan solusi yang dapat dilakukan yaitu peningkatan pemahaman dan keterampilan warga masyarakat melalui pelatihan penerapan mesin penetas telur dan peningkatan omzet warga masyarakat melalui inisiasi peluang usaha penjualan anak itik yang ditetaskan dengan mesin penetas telur.

Untuk menyelesaikan masalah dilakukan dengan pembuatan mesin penetas telur, pelatihan dan pendampingan penggunaan mesin penetas telur dan evaluasi.

\section{HASIL DAN PEMBAHASAN}

Hasil dari kegiatan ini adalah tersedianya mesin penetas telur. Pembuatan dan pengujian mesin penetas telur memerlukan waktu kurang lebih 1 bulan dengan alat-alat dan bahan yang sangat mudah diperoleh di pasaran dengan harga yang terjangkau. Mesin ini memiliki kapasitas 80 telur dengan konsumsi daya 20 watt. Mesin penetas telur dibuat melalui beberapa proses yaitu perancangan, perakitan, dan ujicoba.
Hasil lain dari kegiatan pengabdian kepada masyarakat ini adalah meningkatnya pengetahuan dan keterampilan masyarakat dalam menggunakan mesin penetas telur di lingkungan Desa Ngrajek. Masyarakat yang sebelumnya hanya mengetahui metode penetasan telur sebatas pada metode penetasan secara konvensional, saat ini sudah dapat menggunakan mesin penetas telur secara otomatis. Hal ini sesuai dengan pernyataan bahwa tanpa bantuan mesin tetas, proses penetasan telur akan memakan waktu lama dan resiko kematian yang lebih besar (Wijayanti, 2015). Penetasan dengan menggunakan mesin tetas, banyak memberikan kemudahan dan sangat cocok untuk pembibitan (Mangisah , 2016)

Keberhasilan mesin penetas telur adalah sekitar $60 \%$ dari telur yang ditetaskan. Keterampilan masyarakat meningkat, dari 10 orang yang mencoba menggunakan mesin penetas telur, sekitar 7 orang warga dapat mengoperasikan dengan baik mesin tersebut.

\section{SIMPULAN}

Mesin penetas telur yang dirancang dapat diterapkan dan dapat memberikan manfaat bagi warga masyarakat di Desa Ngrajek untuk lebih meningkatkan wawasan dan pengetahuan warga tentang teknologi penetas serta produktivitas warga yang berprofesi sebagai peternak itik.

\section{DAFTAR PUSTAKA}

Ahaya, R., \& Akuba, S., (2013). Rancang Bangun Alat Penetas Telur Semi Otomatis. Jurnal Teknologi Pertanian Gorontalo (JTPG), 3(1), 44-50.

Anonim. (2013). Profil Desa Ngrajek, Kecamatan Mungkid. http://desangrajek.magelangkab.go.i d/index.php/first/artikel/32. Diakses tanggal 15 November 2018. 
Rawung, V.R.W., \& Utiah, W., (2018). Aplikasi Mesin Tetas Pada Ayam Kampung, IbM Kelompok Peternak Ayam Kampung Desa Tenga. Prosiding Seminar Nasional Pengembangan Unggas Lokal di Indonesia, 109-113.

Mangisah, I., \& Sukamto, B., (2016). Pelatihan Budidaya Itik Secara Semi Intensif Dan Penetasan Telur Di Desa Kebakalan Banjarnegara. Jurnal Info, XVIII (1), 13-28.

Sandi, S., Indra, A., Sari, M.L., \&Y osi, F. (2018). Penerapan Sistem Kawin Sodok dan Mesin Tetas Meningkatkan Produktivitas Itik Pegagan. Jurnal Pengabdian Sriwijaya. 3 (2), 274-281.

Suyatno., (2005). Otomatisasi Mesin Tetas Untuk Meningkatkan Produksi DOC (Day Old Chick) Ayam Lurik dan Efisiensi Usaha. Jurnal Dedikasi, 2, $17-25$

Wijayanti, E. S., \& Setiawan, Y., (2015). Pemanfaatan Mesin Tetas Telur untuk Peningkatan Sektor Peternakan di Desa Lalang Kabupaten Belitung Timur. Jurnal Pengabdian Kepada Masyarakat, 2 (2), 57-63. 